\title{
Improvised Nuclear Device Response Training Materials
}

E. J. Olsen and B. R. Buddemeier

August 2, 2010 
This document was prepared as an account of work sponsored by an agency of the United States government. Neither the United States government nor Lawrence Livermore National Security, LLC, nor any of their employees makes any warranty, expressed or implied, or assumes any legal liability or responsibility for the accuracy, completeness, or usefulness of any information, apparatus, product, or process disclosed, or represents that its use would not infringe privately owned rights. Reference herein to any specific commercial product, process, or service by trade name, trademark, manufacturer, or otherwise does not necessarily constitute or imply its endorsement, recommendation, or favoring by the United States government or Lawrence Livermore National Security, LLC. The views and opinions of authors expressed herein do not necessarily state or reflect those of the United States government or Lawrence Livermore National Security, LLC, and shall not be used for advertising or product endorsement purposes.

This work performed under the auspices of the U.S. Department of Energy by Lawrence Livermore National Laboratory under Contract DE-AC52-07NA27344. 


\section{Table of Contents}

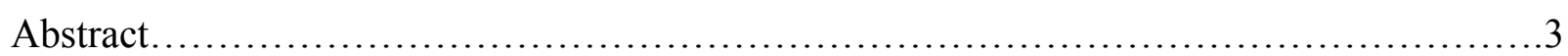

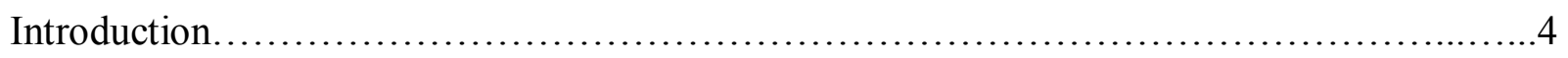

Project Definition.............................................................

Results and Discussion...........................................................

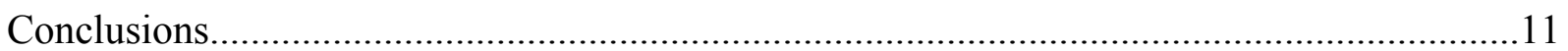

This work performed under the auspices of the U.S. Department of Energy by Lawrence Livermore National Laboratory under Contract DE-AC52-07NA27344. 
Training Materials 3

\begin{abstract}
Nuclear terrorism is a very real threat to the American people. The best way to prepare for, and respond to, terrorist events is to plan for them ahead of time. Research done at Lawrence Livermore National Laboratory (LLNL) has already been conducted on what will happen following the detonation of a low-yield, ground-level nuclear device. Even though this knowledge exists, many cities have not begun to prepare for nuclear terrorism events. This project took the scientific research presentations and publications developed at LLNL and turned them into training materials that use clear language without scientific terminology, and can be easily understood by response personnel. These materials model and analyze the detonation of an Improvised Nuclear Device (IND) in a major metropolitan area. The information contained in these materials explains that survival after the detonation of an IND is possible, and seeks to inform readers on various topics related to the detonation of an IND. Creation of these materials required an understanding of the research behind IND response planning, including building protection factors, radiological fallout, weather patterns and understanding how emergency response happens in an urban environment. The result is a suite of training modules for instructors and students: Fallout, Prompt Effects, Response and Shelter-Evacuation Strategies. These modules are designed so that they may be taught as a combined, full course, or taken as individual modules. Upon completion of an individual module, or the entire set, a person will have a greater understanding, and increased background knowledge, on topics related to a small-scale nuclear attack. These training modules are intended to give an overview of topics necessary to understand what will happen after detonation of an IND and provide suggestions and strategies for response and evacuation. They are not intended to provide a substitute to local, regional, state and national response planning for a nuclear attack. These guides were designed with the intent to act as guidelines and starting points for further extensive planning by all levels of government. By gaining an overview of IND related topics, there is a hope that response planning officials will realize the importance of planning as well as the survivability of such an event with proper planning.
\end{abstract}




\section{Introduction}

This project helps support a larger project on response planning for a 10 kiloton (lowyield), ground-level nuclear detonation, also referred to as an improvised nuclear device (IND), in a major metropolitan area. The overall goal of this project is to help improve national preparedness for response to the aftermath of a nuclear detonation. The Planning Guidance for Response to a Nuclear Detonation, Second Edition" ${ }^{1}$, states that

One of the most catastrophic incidents that could befall the United States (US), causing enormous loss of life and property and severely damaging economic viability, is a nuclear detonation in a US city. It is incumbent upon all levels of government, as well as public and private parties within the US, to prepare for this incident through focused nuclear attack response planning... Local and State community preparedness to respond to a nuclear detonation could result in life-saving on the order of tens of thousands of lives ( $p$. 8).

Even though research has already been done by Lawrence Livermore National Laboratory (LLNL) and other national laboratories on the effects and survivability of a low-yield nuclear detonation, most major cities have not yet begun to fully plan to respond to a terrorist event of this magnitude.

One specific goal of this project is to make people aware that a low-yield nuclear attack will not be the "nuclear Armageddon" situation that most think of when they hear of a nuclear detonation. While a low-yield attack will likely destroy a portion of the given city, it will leave most of the surrounding area intact and able to respond to the disaster (Fig. 1). There will be many victims within the areas radiating outwards from the detonation site that need medical care for blast injuries and radiation exposure, but still have a chance for survival if they are able to receive medical aid. Also, many will have a chance of avoiding deadly doses of radiation from fallout exposure if they can seek an adequate shelter.

\footnotetext{
${ }^{1}$ Developed by The National Security Staff Interagency Policy Coordination Subcommittee for Preparedness \& Response to Radiological and Nuclear Threats; June, 2010
} 
Fig. 1 Potential Damage Zones for a $10 \mathrm{kT}$ Detonation

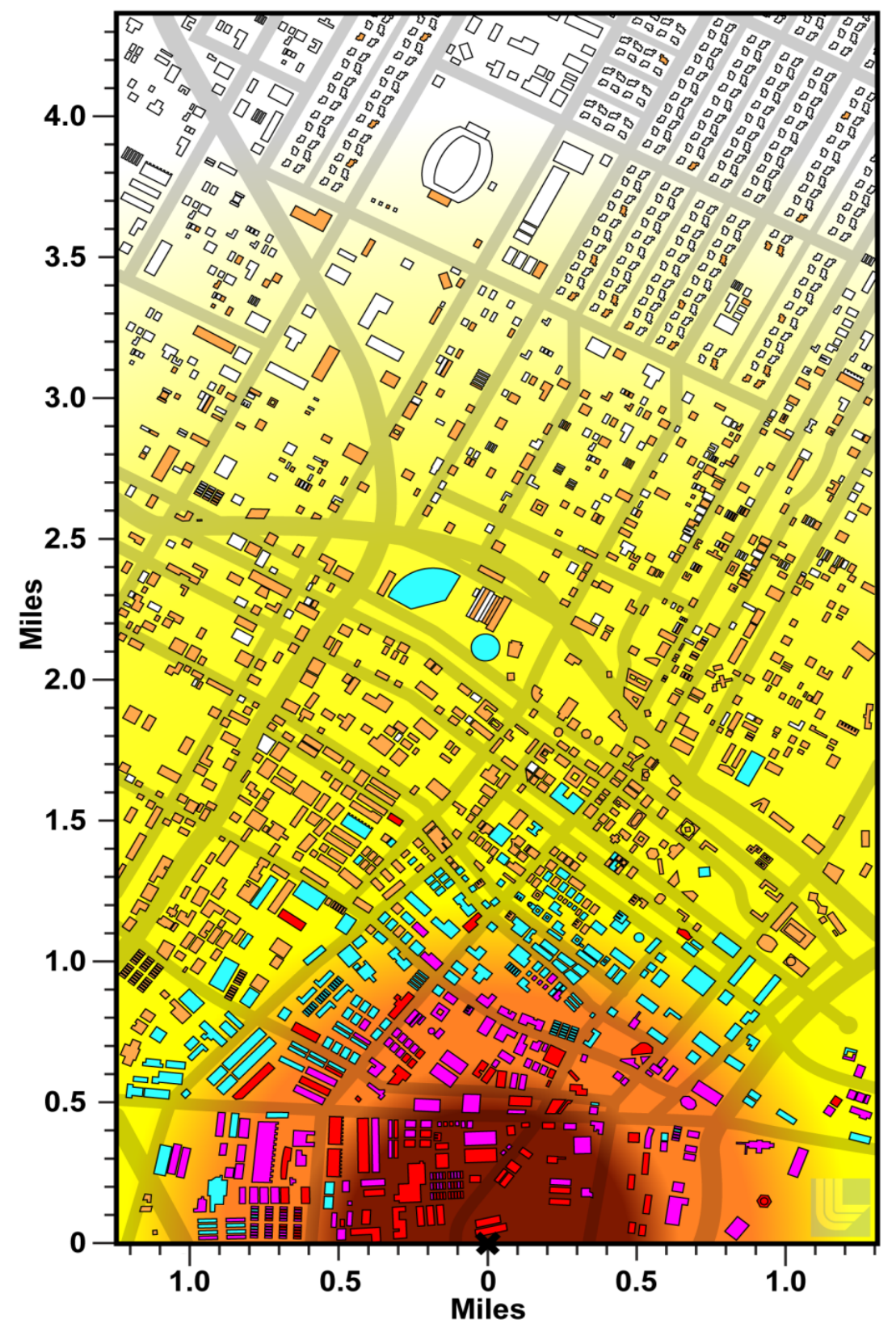

\section{Light Damage (LD) Zone:}

Windows broken, mostly minor injuries that are highly survivable even without immediate medical care

Moderate Damage (MD) Zone: Significant building damage and rubble, downed utility poles, overturned automobiles, fires, many serious injuries. Early medical assistance can significantly improve number of survivors

Severe Damage (SD) Zone: Most buildings destroyed, hazards and radiation initially prevents entry into the area; low survival likelihoods.

$\times$ Notional 10KT Detonation
Structural Damage
$\diamond$ Buildings Collapsed
$\diamond$ Buildings Severe Damage
$\square$ Buildings Moderate Damage
$\checkmark$ Shattered Glass Injuries
$\diamond$ Possible window damage without injury 
One of the most interesting findings of the larger project is that potentially 100,000 s of lives can be saved through knowledge on how to shelter-in-place, or to seek shelter in the immediate vicinity, following an attack. This is due to the initially high levels of fallout radiation followed by its rapid decay (Fig. 2). Most commercial, and many residential, spaces offer adequate protection against radiological fallout (Fig. 3). The Planning Guidance defines adequate protection as a "shelter that protects against acute radiation effects, and significantly reduces radiation dose to occupants during an extended period" (p. 69). In many cases, simply getting into adequate shelter will be enough to save someone's life. This could be something as simple as seeking shelter in a basement or underground parking garage. The only way people will know to do these things, however, is through pre-event awareness and planning. Once people are more aware of the survivability of a nuclear attack, it is likely that their desire to begin planning will increase.

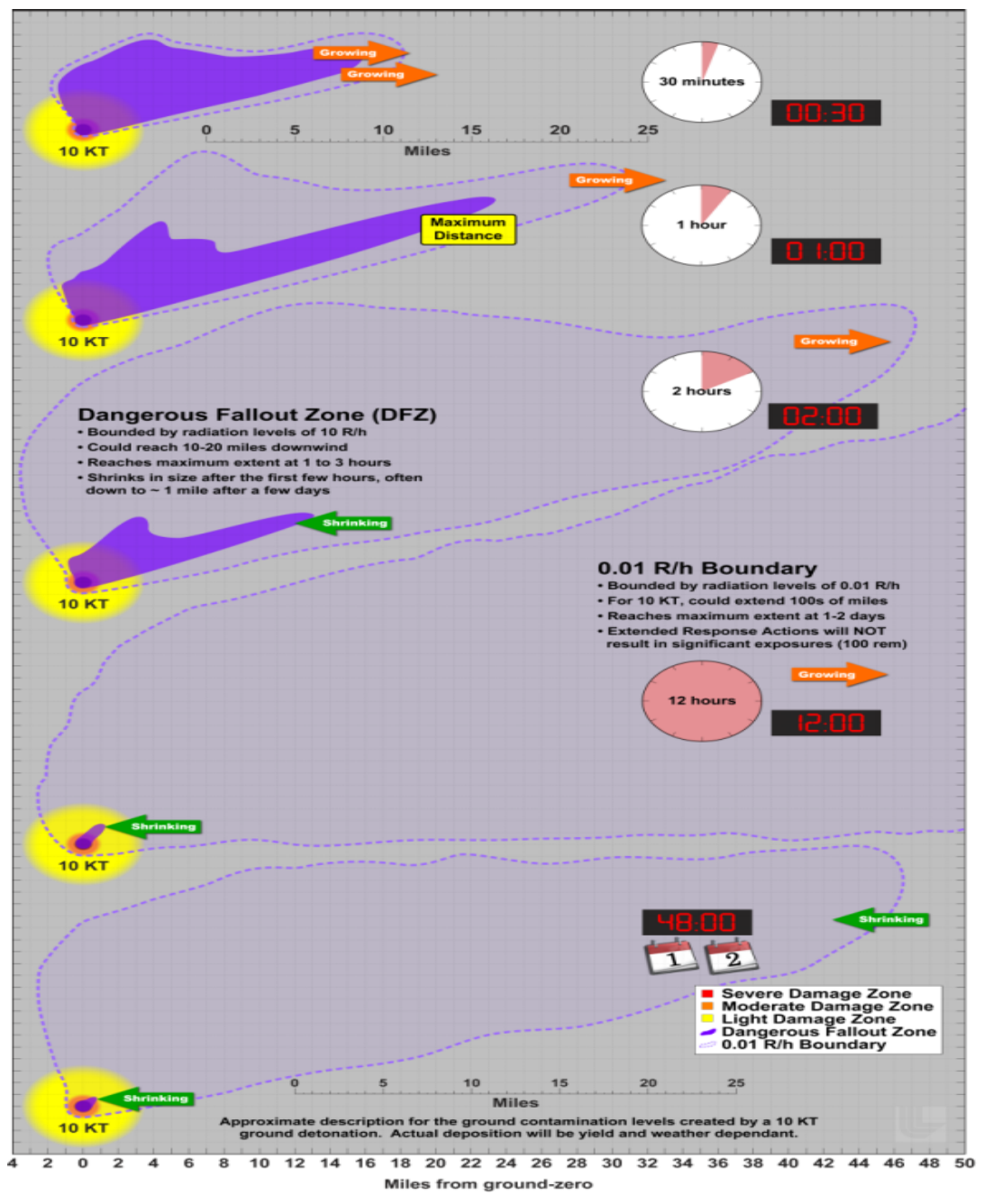

Fig. 2 Radiological Decay in Hours 
Much of the work for this project is done to support federal, state and local agencies in creating emergency response plans for a low-yield attack. This is done by creating modules with information on what happens after a nuclear bomb detonates, including how fallout works and the types of injuries and structural damage likely to occur immediately following the blast. This project also outlines response strategies, and gives advice on how to shelter-in-place and when to evacuate. This project bases its information off of existing research conducted in the early 1950s on radiological fallout, as well as the extensive work done by LLNL, as well as other national laboratories and technical organizations.

\section{Project Definition}

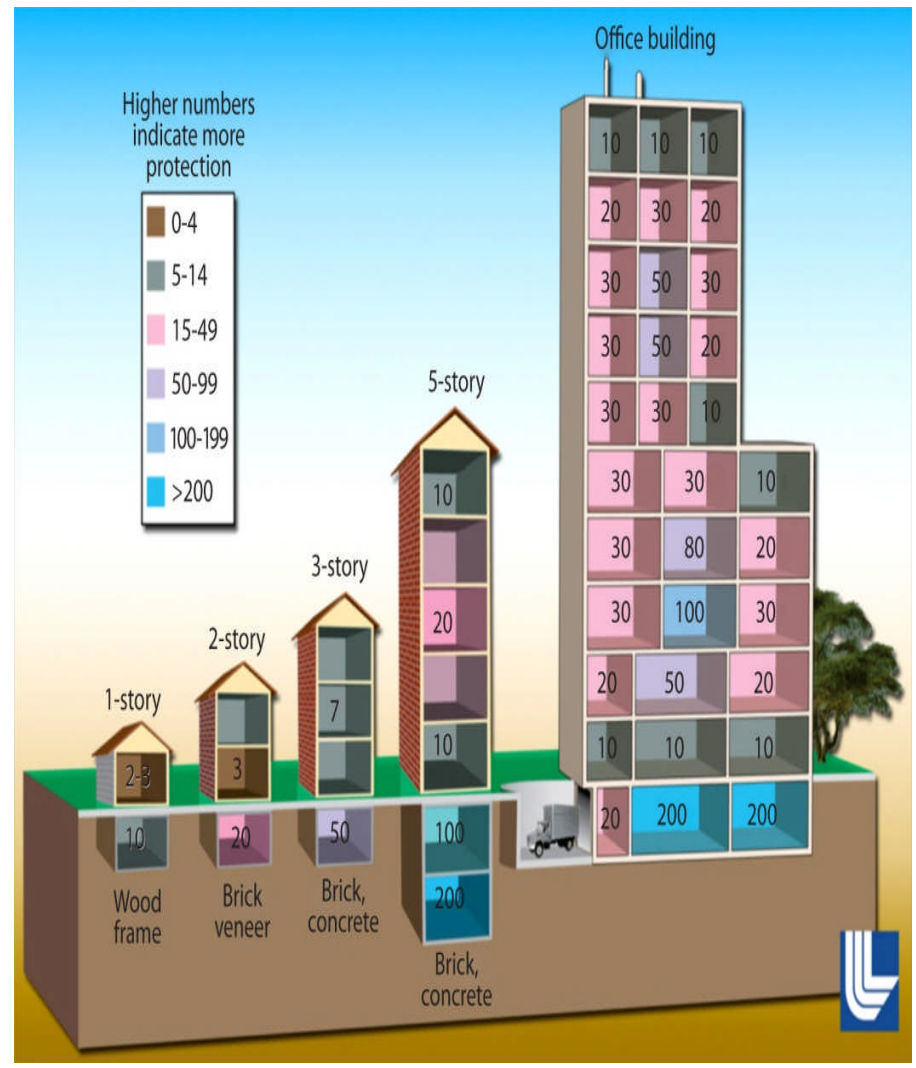

Fig. 3 Protection Factors by Building Type

This project needed to take the scientific research, federal documents and presentations (Fig. 4) and turn them into training materials for responders and the public. These guides needed to be easily understood, and geared towards first responders; free from scientific terminology. The guides contain the facts and information necessary to stress the importance of planning for a low-yield nuclear attack, as well as the information necessary to do so.

\section{Fig. 4 Examples of Scientific Publications Used in this Project}

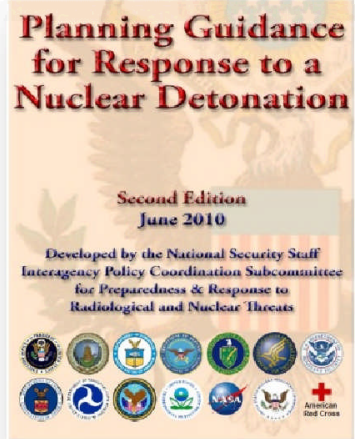

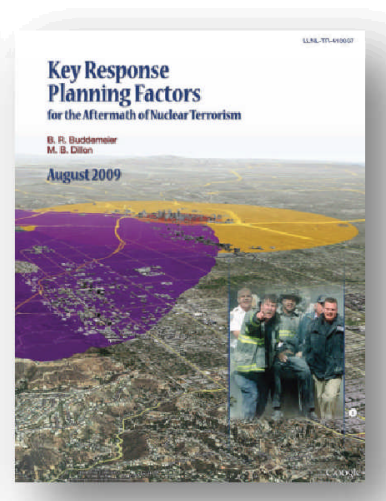

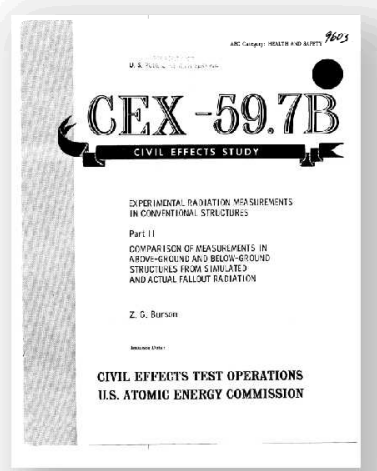

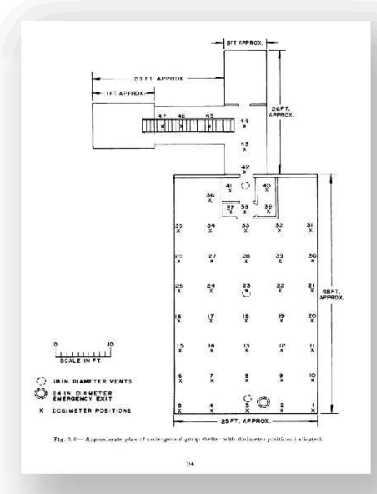




\section{Method of Solution}

A PowerPoint produced by Brooke Buddemeier, LLNL, was used as the framework for the training materials. Buddemeier's presentation contained five topics related to the after-effects of nuclear terrorism, as well as his own original animations and movies (Fig. 5) within the slides. In addition to presentations, publications and federal documents, the slides contained in Buddemeier's presentation were used as the starting point, and, from there, turned into training materials suitable for use by responders.

\section{Fig. 5 Movie Example}

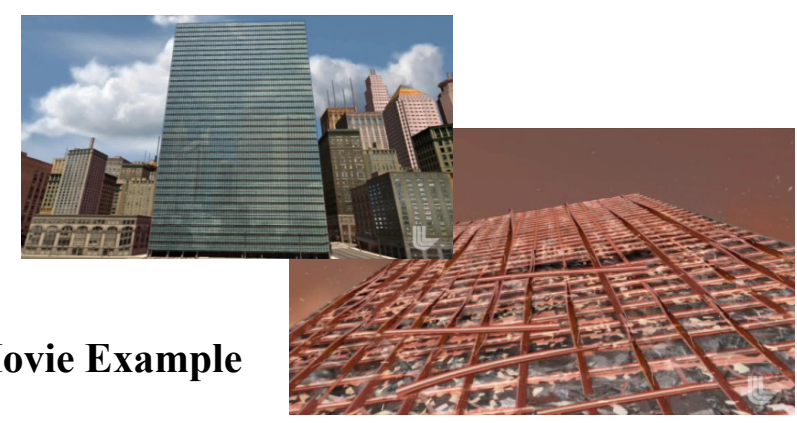

In addition to the recent scientific assessments of several other national laboratories, a literature review of documents from the 1950s was undertaken. These documents were a compilation of articles written by the U.S. Atomic Energy Commission on radiological fallout testing in different housing types. The result of this literature review is a document containing vital information from these articles suitable for fast cross-referencing. These articles provided an overview on the concept of Protection Factors, or the level of protection a particular location within a building offers against radiological fallout

\section{Results and Discussion}

The information from this material, the research conducted at LLNL, and various federal documents on nuclear response planning, provided the basis for a suite of training products for the first responder and emergency management communities. This project took scientific research

\begin{tabular}{|l|l|}
\hline Module Name & Module Objective \\
\hline Prompt Effects (Los Angeles) & $\begin{array}{l}\text { To give an overview of the prompt } \\
\text { effects that follow detonation of an } \\
\text { IND. This includes injury, structural } \\
\text { damage and prompt radiation and } \\
\text { thermal exposure. }\end{array}$ \\
\hline $\begin{array}{l}\text { DHS IND Modeling and Response } \\
\text { Planning Overview }\end{array}$ & $\begin{array}{l}\text { To orient emergency response personnel } \\
\text { on current improvised nuclear } \\
\text { detonation response planning activities } \\
\text { within the federal government. }\end{array}$ \\
\hline Response Strategies & $\begin{array}{l}\text { To give an overview of response efforts } \\
\text { necessary following detonation of an } \\
\text { IND. }\end{array}$ \\
\hline $\begin{array}{l}\text { Shelter and Evacuation Strategies (Los } \\
\text { Angeles) }\end{array}$ & $\begin{array}{l}\text { Explains the life-saving strategies that } \\
\text { can work after detonation on an IND. } \\
\text { This includes sheltering-in-place, and } \\
\text { the basics of informed evacuation. }\end{array}$ \\
\hline Fallout Effects (Los Angeles) & $\begin{array}{l}\text { Gives an introduction to the basic } \\
\text { principles of fallout, how it changes in } \\
\text { time and space, as well as the planning } \\
\text { guidance zones and definitions. }\end{array}$ \\
\hline $\begin{array}{l}\text { Give an overview of prompt effects } \\
\text { including injury, structural damage and } \\
\text { radiation levels. Also review recent } \\
\text { studies and current understanding of } \\
\text { nuclear effects, define planning } \\
\text { guidance zones and review response } \\
\text { strategies. }\end{array}$ \\
\hline Prompt Effects (Washington D.C.)
\end{tabular}

Fig. 6 Module Matrix 
data and turned it into a set of documents that are easy to follow, appealing to view, and applicable to the emergency management and response communities. The final, finished product is a suite of five separate training modules: Federal Planning, Prompt Effects, Fallout Effects Response and Shelter-Evacuation Strategies (Fig. 6). Each of these modules includes an instructor guide which follows a set of PowerPoint slides, and a student handout which follows the presentation. These modules are designed so that they may be taught as a combined, full course, or taken as individual modules. Upon completion of an individual module, or the entire set, a person will have a greater understanding, and increased background knowledge, on topics related to a low-yield nuclear attack.

\section{Instructor Guides}

These guides follow along with Buddemeier's presentation, but are designed so that an instructor may lead his or her own presentation based on the PowerPoint slides. They contain sample scripts to accompany the presentation; all of the wording within is written in clear, concise language free from scientific terminology (Fig. 7).

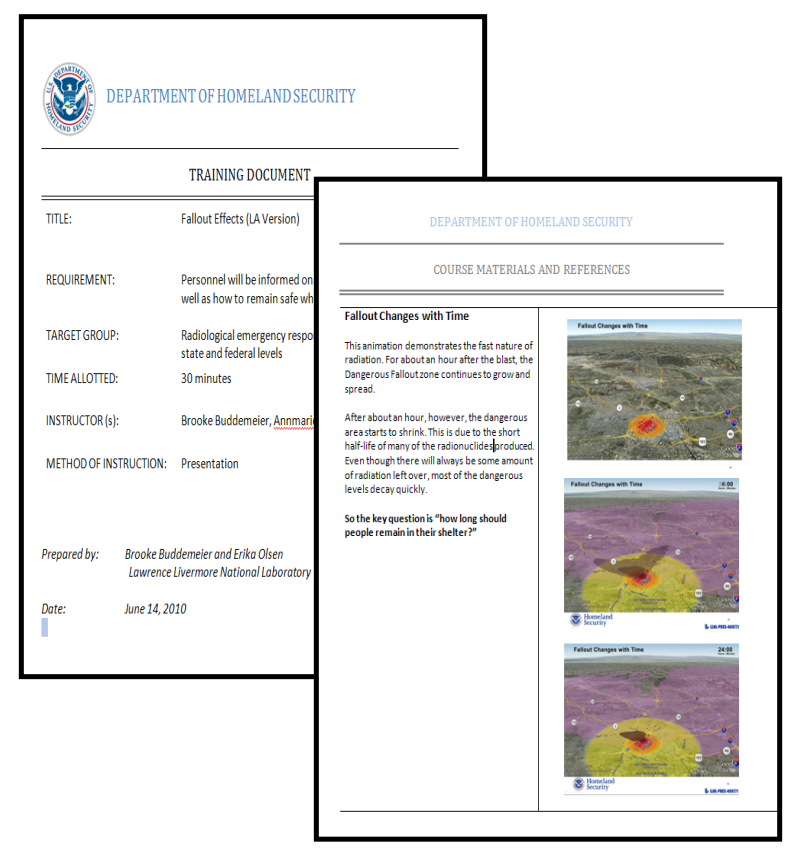

Fig. 7 Sample Instructor Guide 


\section{Student Handouts}

These handouts accompany the instructor guides and are given out to students. They follow along with the PowerPoint presentation, but contain greater detail. They are designed to supplement the material, and could, ideally, provide a brief overview of the topic covered even as a stand-alone guide (Fig. 8).

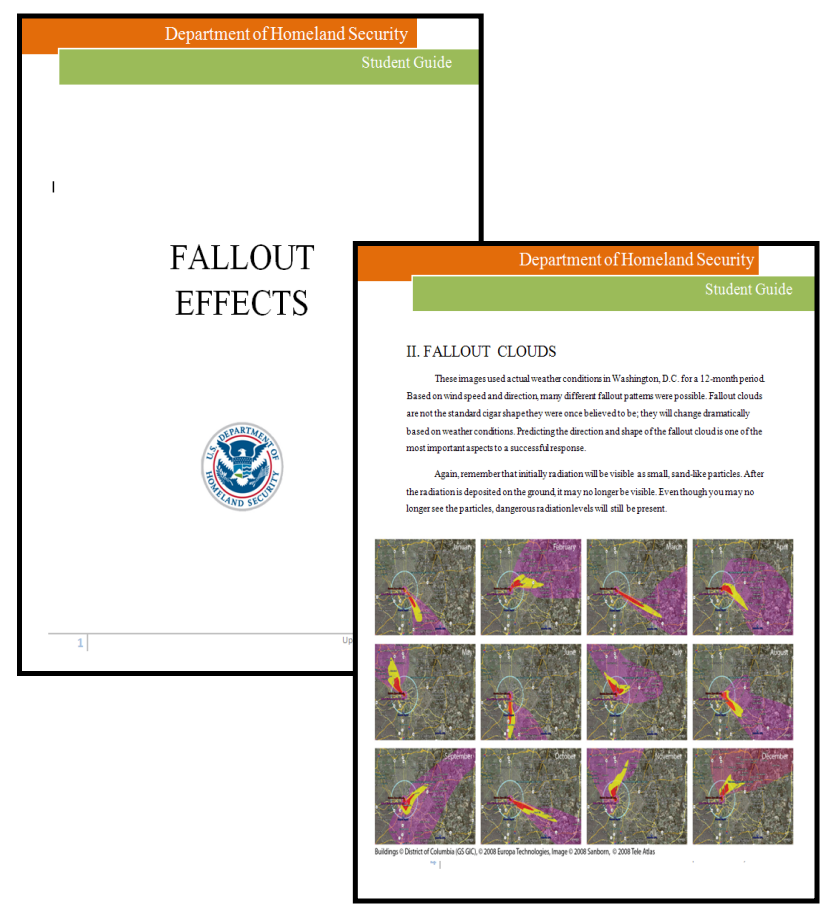

Fig. 8 Sample Student Handout

These training modules are intended to give an overview of topics necessary to understand what will happen after detonation of an IND, and provide suggestions and strategies for response and evacuation. They are not intended to provide a substitute to local, regional, state and national response planning for a nuclear attack but provide additional information and references for the student as they participate in training. By gaining an overview of IND related topics, there is a hope that response planning officials will realize the importance of planning, as well as the survivability of such an event. 


\section{Conclusions}

These training materials give an introduction and overview to topics necessary to understand, and respond to, the detonation of an IND in a major metropolitan area. These guides should be used in conjunction with further planning by all levels of government to prepare for a low-yield nuclear attack.

Currently, the materials originally designed for this project are in the process of being converted to the LLNL Global Security format for use in their training presentations, and efforts are underway to make them available as part of a Federal Emergency Management (FEMA) training program. The challenge remains to start a public awareness campaign on how to survive the detonation of an IND. These training guides will, hopefully, be the start of such a campaign. 